\title{
Current management strategies to target the increasing incidence of diabetes within Pakistan
}

This article was published in the following Dove Press journal: Diabetes, Metabolic Syndrome and Obesity:Targets and Therapy

\author{
Abdul Basit ${ }^{1}$ \\ Asher Fawwad ${ }^{2}$ \\ Shaista Ali Siddiqui 3,4 \\ Kulsoom Baqa ${ }^{4}$ \\ 'Department of Medicine, Baqai \\ Medical University, Baqai Institute \\ of Diabetology and Endocrinology \\ Karachi, Karachi, Pakistan; \\ ${ }^{2}$ Department of Biochemistry, \\ Baqai Medical University, Research \\ Departments, Baqai Institute of \\ Diabetology and Endocrinology \\ Karachi, Karachi, Pakistan; ${ }^{3}$ Kaizen \\ Management Consultancy, Sharjah, \\ United Arab Emirates; ${ }^{4}$ Research \\ Department, Baqai Institute of \\ Diabetology and Endocrinology, Baqai \\ Medical University Karachi, Karachi, \\ Pakistan
}

\begin{abstract}
According to the recently published National Diabetes Survey of Pakistan (NDSP 2016-2017), the prevalence of diabetes is $26.3 \%$. Hence, Pakistan has around 27.4 million people $>20$ years of age suffering with diabetes. Compared to previous estimation of having around 7 million diabetic patients based on a survey done in 1994-1998, the figures are disturbingly alarming. The four main strategies to tackle the rising incidence of diabetes in Pakistan are as follows: 1) creating multidisciplinary teams through capacity building of the health care professionals (HCPs), including doctors, dieticians, diabetes educators, diabetes foot assistants, and program managers in standardized evidence-based protocols, enhancing their knowledge and skills in managing diabetes and their related comorbidities; 2) promoting primary prevention and awareness all over Pakistan using screening methods such as Risk Assessment of Pakistani Individuals for Diabetes (RAPID); 3) defining strategies for the management and prevention of diabetes and its complication through forums such as the Pakistan Diabetes Leadership Forum (PDLF); and 4) implementing a nationwide diabetes care program including registration, treatment, and referral protocols. The epidemic of diabetes in an under-resourced and overburdened health care system of Pakistan poses a serious challenge not only for the doctors but also for the multiple stakeholders involved in the community systems. There is a need for promoting and screening the population using RAPID and registering people with diabetes through Diabetes Registry of Pakistan (DROP). Future priority areas and interventional strategies shall include the following: implementing a diabetes health care service model in both rural and urban population using evidence-based clinical guidelines along with lifestyle modifications (LSMs) and prevention policies. Current management strategies and proposed future directions may successfully target the increasing incidence of diabetes.
\end{abstract}

Keywords: non-communicable diseases, primary prevention, health care service model, guidelines

\section{Background information}

The recently published National Diabetes Survey of Pakistan (NDSP 2016-2017) has served as an eye opener not only for health care professionals (HCPs) but also multiple stakeholders including policy makers. The repercussions have already started within Pakistan and are increasingly felt regionally and internationally. NDSP 2016-2017 was conducted by the Ministry of National Health Services, Regulation and Coordination (MNHSRC), Pakistan Health Research Council (PHRC), Diabetic Association of Pakistan (DAP) and WHO Collaborating Center, and Baqai Institute of Diabetology and Endocrinology (BIDE). ${ }^{1}$

Pakistan is a country with limited resources and various socioeconomic strata. It has a population of 207.77 million and an average annual growth rate of $2.4 .^{2}$ Gross domestic product (GDP) of Pakistan has reached 5.28\% in 2016-2017, highest in the

Diabetes, Metabolic Syndrome and Obesity:Targets and Therapy 2019:12 85-96

Dovepress in


last 10 years. $^{3}$ The total health expenditure in the current financial year 2016-2017 is PKR 145.97 billion, which is a $9 \%$ increase over the same period of last year. Still, according to the latest World Bank report, Pakistan per capita health spending is less than WHO low-income countries, ie, USD 36.2 compared to USD 86 , respectively. ${ }^{4}$

A partnership of public and private health care system exists, but not properly equipped and trained to manage the increasing prevalence of non-communicable diseases (NCDs). About 0.1 million lady health workers were trained to provide essential maternal and child health services under the supervision of government covering around $60 \%$ of the population, but lacking NCD education. ${ }^{5}$ General physicians (GPs) are providing basic health care to $75 \%$ of the urban population. However, the GPs were not properly trained to manage and prevent diabetes and related NCDs. ${ }^{6}$

According to NDSP 2016-2017, the prevalence of diabetes is $26.3 \%$. Hence, Pakistan has around 27.4 million people $>20$ years of age suffering with diabetes. ${ }^{7}$ Compared to previous estimation of having around 7 million diabetic patients based on a survey done in 1994-1998, the figures are disturbingly alarming. ${ }^{8}$ Likewise, around 47 million people are suffering from hypertension. Obesity, according to the Asian cutoff, is highly prevalent with every other person suffering from it. ${ }^{1}$

The rapid increase in diabetes is mainly ascribed to ecological and psychological changes. The main contributors are sedentary lifestyle, including Internet and TV usage, and calorie-rich diets leading to increasing obesity. ${ }^{9,10}$ The prevalence of obesity among young adult is now $15 \%$, and it is one of the main causative factors for the epidemic of diabetes in both urban and rural population of Pakistan. ${ }^{11}$

Pakistan as a low-resource country is also facing issues related to maternal malnutrition and low birth weight. Nutrition Landscape Information System (NLIS) and country profile of Pakistan report a low birth weight of as high as $32.0 \%$ and a maternal mortality rate of 178 per $1,00,000$ live births. ${ }^{12}$ Intrauterine growth retardation exposes the fetus to increasing risk of future type 2 diabetes mellitus (T2DM). These are already documented to be independent risk factors for T2DM. ${ }^{13}$

Diabetes-related chronic complications are also highly prevalent. The prevalence of peripheral vascular disease (PVD) is 5.3\% and that of cerebrovascular disease is $4.5 \% .^{14}$ The prevalence of microvascular complications such as retinopathy, nephropathy, and neuropathy is $15.8 \%, 31.0 \%$, and $48.7 \%$, respectively. ${ }^{15}$ Unfortunately, $4 \%$ of the diabetic patients are affected by diabetic foot ulcers (DFUs). ${ }^{16}$ Considering current prevalence of diabetes, it is estimated that in Pakistan 1.09 million people suffer from DFU (Table 1).
Table I Micro and macrovascular complication rate in Pakistan

\begin{tabular}{|l|l|l|}
\hline & \multicolumn{2}{|l|}{ Micro and macrovascular diseases } \\
\hline Study & Name of complications & Percentage \\
\hline Macrovascular complication \\
\hline Zia et al (2016) ${ }^{14}$ & Peripheral vascular disease & 5.35 \\
& Stroke & 8.45 \\
& Ischemic heart disease & 28.17 \\
\hline Basit and Nawaz & Diabetic foot ulcer & 4 \\
$(2013)^{16}$ & & \\
\hline Microvascular complication & 15.8 \\
\hline Abro et al & Retinopathy & 31 \\
$(2018)^{15}$ & Nephropathy & 48.7 \\
\hline
\end{tabular}

The economic and psychological impact of DFU is considerable. The direct cost of treating DFUs was estimated at 2004-2005. During that year, the average monthly amount spent by a family was PKR 9,121, out of which the per capita health expenditure was PKR 220.58, which is highly suggestive that health care is one of the least priorities. Then, if a person with diabetes gets a foot ulcer, the cost of its treatment is estimated to be more than a whole family's health budget for 10 years. ${ }^{17}$ Taking into account the abovementioned background information, four main strategies to target the increasing incidence of diabetes in Pakistan were considered and are detailed subsequently. ${ }^{18}$

\section{Capacity building}

It has to be realized that even the best economies worldwide cannot tackle the burden of diabetes and NCDs at secondary and tertiary care levels. Hence, capacity building of primary care physicians (PCPs) is the most cost- and time-effective intervention. ${ }^{19}$ Some institutes have been running courses for family physicians for nearly 2 decades. ${ }^{20}$ The basic objective is to train in current diabetes management through evidencebased curricula and latest skills through structured courses. ${ }^{21}$ Diabetes and endocrinology as a specialty have been struggling in Pakistan to get their recognition for around 15 years. Pakistan Endocrine Society (PES) has been the forerunners in persevering with the cause, and eventually a second fellowship in endocrinology was offered by the College of Physicians and Surgeons Pakistan (CPSP) in 2009. ${ }^{22}$ Hence in the last decade, there have been a number of consultant diabetologists and endocrinologists trained with second fellowship contributing at secondary and tertiary care levels.

Diabetes education, as an important integral part of diabetes care, was introduced in the country 20 years ago. Unfortunately, it has not been initially supported by the health care system, both in public and private sectors. In the last few years, the trend of certificate and diploma courses 
in diabetes education is spreading all over Pakistan, mostly because of the realization of the fact that diabetes educators are an important part of the multidisciplinary care team. ${ }^{23}$ Limited resources and accelerating burden of diabetes and NCDs are warranting early intervention at the policy level to introduce, regularize, implement, and integrate not only diabetes educators but also NCD educators and health educators into the system. Various institutions in public and private sectors have the capacity to train such work force, which no doubt is the most cost- and time-effective approach for dealing with the epidemic. ${ }^{24}$ The pioneering work in diabetes education has been acknowledged by the International Diabetic Federation (IDF) since 2009 (BIDE has been designated as an IDF center of education among the six centers of the world). At present, the IDF is in the process of developing such centers worldwide, and Pakistan is privileged to have one of the IDF Center of Education and IDF Center of Excellence. ${ }^{25}$

Foot care services worldwide have been successfully developed through the concept of Multidisciplinary Diabetic Foot Care Team (MDFCT). In Pakistan, BIDE led to the development of this concept and has changed the understanding of diabetic foot care at various levels in the country. Pediatric services initially were scarcely available and were very expensive. Concept of diabetic foot care assistants (DFCAs) was coined by BIDE. Personnel experienced in wound dressing and management are trained for 6 weeks through a structured course. ${ }^{26}$ Pakistan Working Group on Diabetic Foot (PWGDF) was established in 2006, and it disseminated the information through regular seminars, events, training courses, and annual conferences. International Working Group on Diabetic Foot (IWGDF) has endorsed these training courses and programs and is replicated in many countries worldwide. These DFCAs are trained for incision and drainage (I\&D), plaster cast (PoP) for Charcot arthropathies, and offloading for non-healing ulcers, and domiciliary dressing service was initiated to cut down not only the direct but also the indirect cost of the foot ulcer management. ${ }^{27}$ In 2007, a nationwide diabetic foot care program was initiated with the seed money from the World Diabetes Foundation (WDF). Step by Step (Sbs) program was started in Pakistan following the successful results in India and Tanzania. Foot care teams, including clinicians and their DFCAs, were trained initially for the basic course and then after a year of experience through an advance course helping in the establishments of diabetic foot clinics. One hundred and fifteen diabetic foot clinics were established in 3 years, and the amputation rate in these clinics was reduced by $50 \% .^{28}$
After reduction of the amputation rate, the next target was a reduction in the development of DFU. Another program with the support of WDF, by the title of footwear for every diabetic (FED), was initiated to achieve this target. Through FED, a nationwide training of footwear technicians has started, and a customized low-cost foot wear is now being developed in many cities of the country. Guidelines for foot management developed by IWGDF and translated in Urdu are disseminated across the country. ${ }^{29}$

Health Research Advisory Board (HRAB) was established in 2012. It is a "think tank" of senior clinicians, researchers, and academicians, who are committed to the mission of "Developing the Research Ecosystem of Pakistan". Members of HRAB represent major technical specialties, medical institutions, and associations and possess relevant expertise to spearhead such a significant component of our health system. Diabetes and related NCDs are among the top priority agenda of HRAB. ${ }^{30}$

Various national and international collaborative programs for research in the field of diabetes are undertaken. One such worth mentioning effort was the collaboration of University of Oslo with Pakistan, India, and Bangladesh to develop MPhils and PhDs through NORAD'S Master's program (NOMA) project. Likewise, nurses, lady health workers, community midwives, and other allied HCPs are being trained more and more, but much more structured and dedicated efforts are needed to combat the epidemic. ${ }^{31}$

\section{Primary prevention and awareness}

Landmark primary prevention studies, such as Diabetes Prevention Study (DPS, Finland), Diabetes Prevention Program (DPP, USA), and others done in China, India, and Pakistan, have proven beyond doubt that diabetes can be prevented. ${ }^{32}$ Primary prevention of diabetes is an important integral part of management strategies in many parts of the world. Also, worth noting is the fact that lifestyle modifications (LSMs) have proven to be more effective than pharmaceutical interventions. ${ }^{33}$ In Pakistan, DAP and WHO Collaborating Center was established in 1966. Awareness campaigns have started since. It was affiliated with IDF in 1967 and is one of its oldest members. DAP has been holding World Diabetes Day program annually in the month of November, including an exclusive session for patient's awareness. BIDE realizing the importance of patient awareness and community involvement started with an annual diabetes awareness walk. ${ }^{34}$ In the last 2 decades, public awareness programs have spread all over Pakistan and approximately 50 cities and towns arrange diabetes awareness walks. 
National Association of Diabetes Educators of Pakistan (NADEP) was established in 2010 with an idea to involve multiple stakeholders in diabetes education programs, especially primary prevention all over Pakistan. Membership was offered to patients, their careers, philanthropists, people from social and electronic media, allied HCPs, and non-HCPs. ${ }^{32}$ NADEP offers an excellent consultative platform to encourage the development and delivery of validated and structured diabetes education nationwide. ${ }^{35}$

For massive population screening, RAPID score has been developed. It is a probability-based algorithm for assessing T2DM risk among the Pakistani population. RAPID is established on screening variables without the need of laboratory tests. ${ }^{36}$ This score is much in line with the Finnish Diabetes Risk Score (FINDRISC) and risk scores developed in Germany, England, and Australia and is a result of nationally conducted prospective studies. The nationwide screening program is planned to be initiated, taking RAPID into consideration. ${ }^{37}$

Hydrie et $\mathrm{al}^{38}$ carried out a study of diabetes and associated risk factors in adolescents targeting the age of 15-25 years in the province of Baluchistan in 2002 and then in 2009. School going children of the age of 8-10 years were studied. Increasing associated risk factors of diabetes among the children and adolescents warrant defining strategies at primary and secondary school levels. Therefore, the planning of diabetes awareness campaigns depends on the age targeted. School going children are given lectures on healthy diet and exercise by their teachers and by school programs. Cooking of healthy breakfast, sports activities, and various games involving physical exercise are encouraged and highlight health interventions to prevent adolescents from diabetes. These strategies have been developed and publicized through social and electronic media, and now it is being used more and more for education. ${ }^{39,40}$

Women and girls with diabetes face multiple challenges because of power dynamics, social inequality, and perceived gender roles in our society. Added to this is the disproportionate distribution of nutrition and lack of facilities for physical activity for women. Women in the reproductive age group are increasingly affected by diabetes, and many pregnancies are complicated by pre-existing diabetes. Added to this is the burden of gestational diabetes mellitus (GDM). GDM should not be perceived as a singular clinical entity, rather it should be considered as trans-generational diabetes that needs to be addressed as a public health problem. It is imperative to integrate GDM with maternal and child health programs. Furthermore, targeting malnutrition as well as obesity present in women of reproductive age group and children must be prioritized as their roles are fundamental for family health and well-being. ${ }^{41}$

\section{Policy planning and advocacy}

The national action plan (NAP) for the management of diabetes was first developed in Pakistan in the mid-1990s. The main role was played by the Ministry of Health and had collaborators such as DAP and Heart File. Since then, four NAPs have been developed, which are comprehensive and include strategies and policies for the management and primary prevention of diabetes. ${ }^{42}$ Unfortunately, because of the multiple factors, none of the action plans have been implemented. After the decentralization of health services from the federal to provincial level, the federal government spent PKR 22.4 billion in 2016-2017 fiscal year on health sector, but remained largely focused on communicable diseases with the exception of cancers. ${ }^{43}$ Only provincial government of Khyber Pakhtunkhwa (KPK) took a lead for managing diabetes through establishing insulin banks in ten main hospitals of KPK in 2014. ${ }^{44}$ However, there is a need to define strategies for the management and prevention of diabetes ensuring accessibility, availability, and affordability of the required tests and medicines and to monitor through the surveillance system ascertaining effectivity. The main role related to implementation of such plans ought to be played by the health policy makers and regulatory bodies in Pakistan. ${ }^{45}$

Pakistan Diabetes Leadership Forum (PDLF) was organized in 2014. It was through the effort of MNHSRC and was cohosted by a wide range of national and international organizations, including the IDF, WDF, DAP, BIDE, PES, Pakistan Institute of Medical Sciences (PIMS), and Sakina Institute of Diabetes and Endocrine Research (SIDER). The forum took place in Islamabad, Pakistan, on March 1-2, 2014. PDLF served as a platform for the key stakeholders in the area of diabetes and related NCDs, including opinion leaders, policy makers, partners in public health, and the media through high-level sessions and panel discussions. The purpose of these policy discussions was to create a network of committed Key Opinion Leaders (KOLs), who can drive the agenda forward in diabetes prevention and care in Pakistan. ${ }^{46}$

Some important noteworthy observations were as follows:

- Maternal and child health issues are inextricably linked with the development of related NCDs and their risk factors. While maternal obesity and diabetes during pregnancy (gestational and pre-existing diabetes) contribute to immediate and long-term health risks for mothers, they also impart a substantial risk for their offspring. 
- Poverty is both a cause and consequence of diabetes and related NCDs, thus posing a direct threat to the health, economic, and social development at the global and national level and threatens the achievement of the United Nations Millennium Development Goal.

- The pressing need to invest in diabetes and related NCD prevention requires multi-sectoral responsibility and action. Considerably more gains can be achieved by engaging all partners and stakeholders in public health and by harmonizing efforts to avert these preventable conditions and to save millions of people from suffering needlessly and dying prematurely. ${ }^{46}$

The key recommendations of the PDLF 2014 to donors, development partners, and UN agencies were as follows.

PDLF encourages the government to support a call for a United National General Assembly special session to discuss and include diabetes and NCDs into the United National Sustainable Development Goals (SDGs). This is done by formulating and adopting integrated policies on the inclusion of screening for diabetes and GDM as part of the national package of essential health care services. Some key recommendations of the PDLF 2014 to donors, development partners, and UN agencies were to conduct a needs assessment and identify resources at the national level and to support an integrated approach to diabetes care and related NCDs.

\section{Diabetes care program at the national level}

Historically, there has been a low level of investment in the management and prevention of NCDs in Pakistan. However, the government, at the national level, had made initial efforts whereby developing NAPs for NCDs. ${ }^{47}$ Presently, the primary health care seems to identify only about $10 \%-20 \%$ of the estimated prevalent T2DM and hypertension cases. The referral to the district level hospital seems to be inadequate even for the available expertise. ${ }^{19}$

In response to the situation outlined earlier, the NCDs and Mental Health Unit, Directorate General Health Services of Pakistan are taking measures to address the challenges in delivering integrated diabetes/hypertension care at the primary health care level. These include ${ }^{18}$ the following:

- Developing integrated care delivery products including lifestyle counseling tool, orientation package for doctors, and allied health professionals.

- Strengthening the district management support functions for integrated care delivery, including district resource mobilization, staff orientation on essential patient screening and care monitoring, and referral linkage.

- The provincial NCDs and Mental Health Program will arrange and conduct orientation sessions for the provincial and district-level trainers. The program will further facilitate the orientation of district staff by providing materials and assisting in training arrangements including paying for participant cost.

- The district-level training institutions (ie, District Health Development Centers [DHDC]) and trainers, with the assistance of the Provincial NCDs \& Mental Health Program, will orient various cadres of care providers, on endorsed program materials.

- At each rural health center and tehsil and district headquarter hospital at least two doctors and three allied health professionals will be oriented on patient screening and education/awareness, as per program protocols. The lady health workers/supervisors associated with the facilities will also be oriented on screening and awareness of lung health, diabetes-cardiovascular disease (CVD), smoking, and mental health. ${ }^{18}$

A Samad Shera with a team of senior colleagues prepared first national clinical practice guidelines for diabetes in 1999. The document had structured management guidance. In 2017, Pakistan's Recommendations for Optimal Management of Diabetes from Primary to Tertiary care level (PROMPT) guidelines were developed by the Advisory Board for the Care of Diabetes (ABCD). PROMPT is a revised version of the first document, based on recent evidence and consensus recommendations, taking into account the resource constraints and hence suggesting cost-effective strategies (Figure 1). ${ }^{42}$

Referral criteria for managing people with diabetes at different levels of care needed are specified in the PROMPT guidelines. Primary care is the first level of contact of an individual with the doctor. Primary care facility is affordable and has diabetes educators as an essential part of the practice. Secondary level in diabetes care is recommended to consists of a multidisciplinary team with a postgraduate degree or specific training of the doctors, diploma-holding diabetes educators, and DFCAs. Tertiary care university hospital shall include an outpatient and inpatient care along with facilities of training and research. Integrated care of a person with diabetes includes physicians with special interest in diabetes or consultant diabetologists and endocrinologists working in liaison with certified diabetes educators and/or nurse specialists and also having dietitians/nutritionists, podiatrists, and/ or DFCAs and other allied medical specialities. ${ }^{47,48}$ 

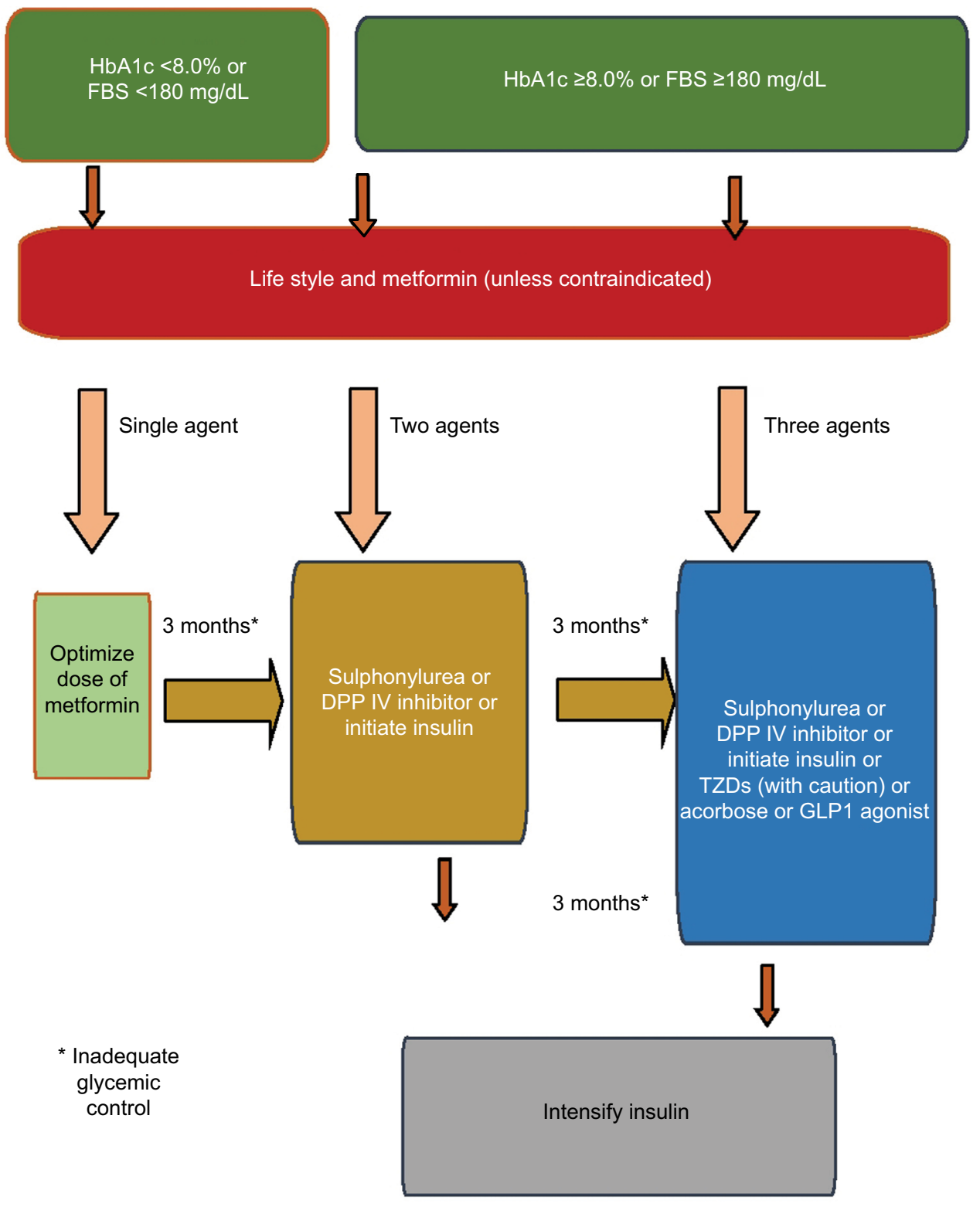

Figure I PROMPT guidelines for the management of T2DM.

Abbreviations: DPP, Diabetes Prevention Program; PROMPT, Pakistan's Recommendations for Optimal Management of Diabetes from Primary to Tertiary care level; T2DM, type 2 diabetes mellitus; TZDs, thiazolidinediones; FBS, fasting blood sugar.

As per the clinical protocol on a national level, LSMs shall be recommended to all. Also, metformin must be suggested to all T2DM subjects regardless of initial BMI, provided there is no contraindication. In line with the WHO recommendation for low-resource countries, sulfonylureas should be the second-line choice. Statin should be added on a priority basis as the main mortality is CVD related. ${ }^{48}$ Angiotensin-converting enzyme (ACE) inhibitor should be prescribed early as chronic kidney disease (CKD) prevention is both cost and time effective. WHO has recommended metformin, sulfonylurea, insulin, aspirin, statin, ACE inhibitor, angiotensin receptor blocker (ARB), and thiazide as the essential medications for the management of diabetes and related NCDs. ${ }^{49-52}$
Self-monitoring of blood glucose (SMBG) is an integral element of diabetes management. $\mathrm{ABCD}$ developed Better Recommendations, Implementation and Guideline development for Health care providers and their Training (BRIGHT) guidelines. It ensures that people with diabetes and their HCPs can have the knowledge and skills to monitor their glycemic level and therapy can be adjusted according to their targets. However, in Pakistan, due to severe gaps in the infrastructure related to health service provision compounded with non-affordability and lack of consensus guidance document, people with diabetes were suffering with the consequences. Therefore, BRIGHT recommendations have been developed keeping in consideration the socioeconomic classes of the patient (Figure 2). ${ }^{53}$ 


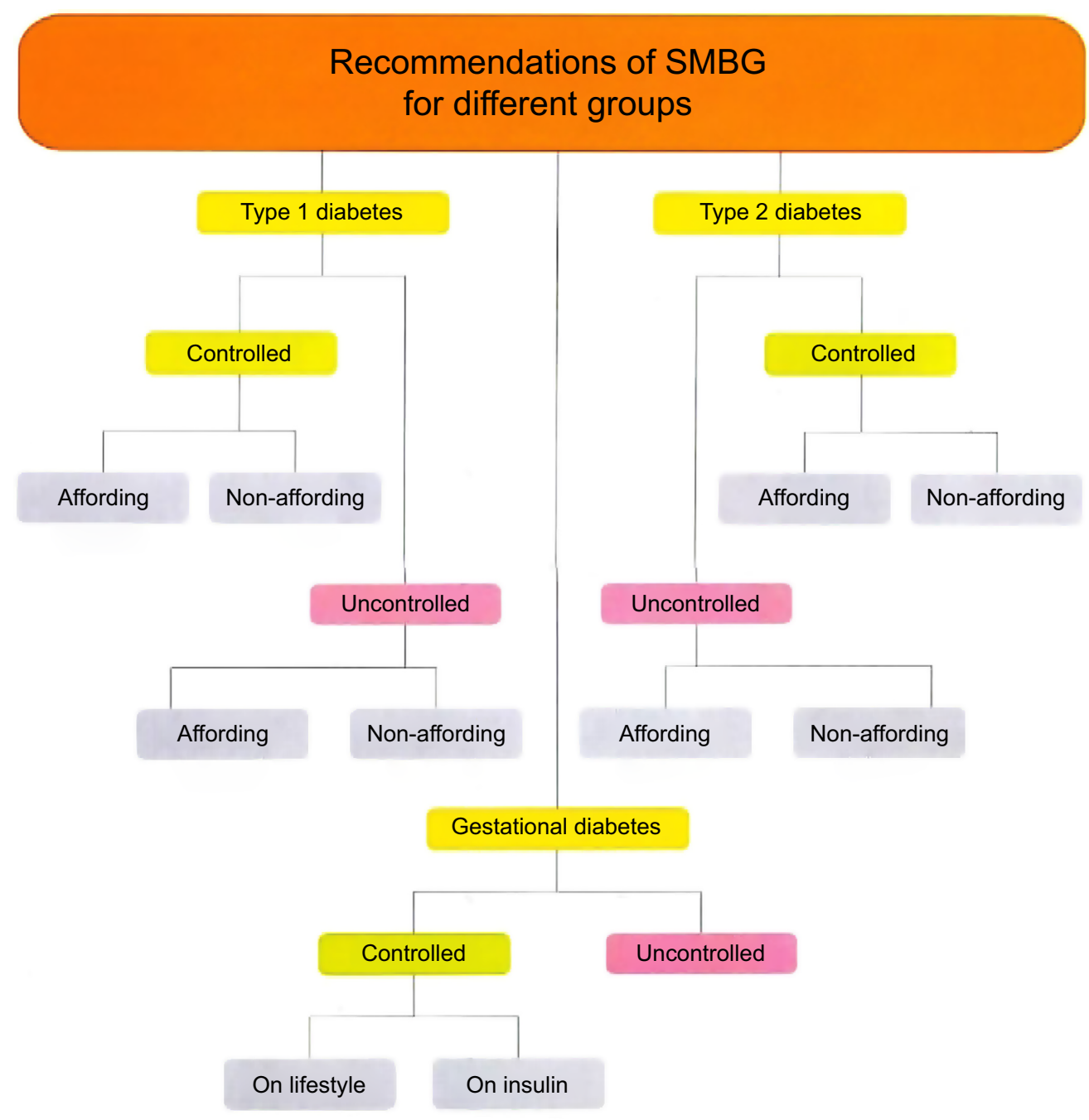

Figure 2 BRIGHT recommendations of SMBG for different groups.

Note: Adapted from Basit A, Khan A, Khan RA. BRIGHT Guidelines on Self-Monitoring of Blood Glucose. Pak J Med Sci. 20I4;30(5):II50-II55. 53

Abbreviations: BRIGHT, Better Recommendations, Implementation and Guideline development for Health care providers and their Training; SMBG, self-monitoring of blood glucose.

Since its establishment in 1999, BIDE has been playing an essential role in educating and training doctors and educators along with the development and maintenance of specialized clinics and has designed a service model for the management of diabetes in Pakistan. According to this model, there is a need to establish 3,000 diabetes clinics at the primary level, 300 secondary care diabetes units, and 30 tertiary care diabetes centers all over Pakistan. BIDE has been working to implement this model since 2014 in collaboration with private and public health organizations through various projects (Figure 3 ).

Insulin My Life (IML) is one of the projects using the same service model for the province of Sindh, Pakistan, and was initiated in 2010. The project started with the aim to help those type 1 diabetes mellitus (T1DM) children to whom insulin was not easily accessible and/or affordable. In the first stage, IML established 33 model clinics for the management of T1DM in Sindh. Initially, the doctors and educators in these centers were given structured training for managing T1DM. Moreover, through IML along with insulin, glucometers, strips, and $\mathrm{HbAlc}$-testing facilities are also provided free of cost. IML has been acknowledged and well collaborated with Life for a Child (LFAC) program of the IDF. ${ }^{54} \mathrm{After}$ the success of this project, BIDE plans to establish it in other provinces of Pakistan. The learning from this project recommends that to sustain the proposed model, an integrated approach and governance strategy need to be incorporated, according to which a diabetic patient must have access to a health facility that provides comprehensive diabetes management. This also requires an information technology (IT) service, so that all the health care providers are able to access patient's data and prompt involvement of relevant specialties can be exercised. 


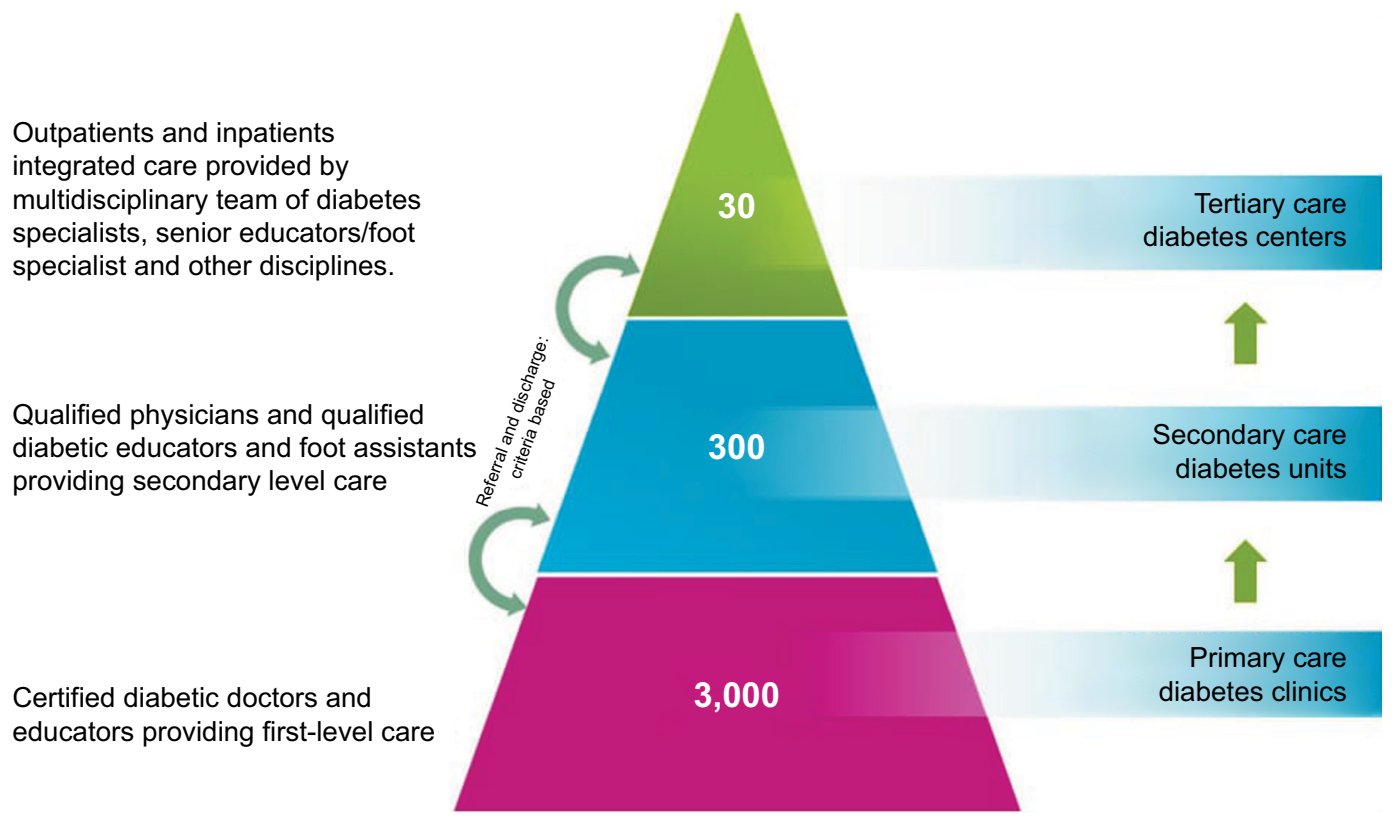

Figure 3 Service model for diabetes care.

Furthermore, its effectiveness can be monitored through risk management and clinical audits.

HRAB of Pakistan has taken the task of developing registries countrywide. BIDE and $\mathrm{ABCD}$ in collaboration with HRAB have started the Diabetes Registry of Pakistan (DROP). It has planned for DROP-1 (type-1 registry), DROP-2 (type-2 registry), DROP-G (registry for GDM), DROP-F (registry for diabetic foot), and DROP-R (diabetes registry for Ramadan). Initially, DROP-1 is established. It aims to register people with T1DM in the country, to ascertain $^{55}$ closest approximation of their total number to provide emergency unit access through website to all people with T1DM and to optimize their day-to-day care. ${ }^{56}$

\section{Future management strategies to target the rising incidence of diabetes in \\ Pakistan}

The epidemic of diabetes in an under-resourced and overburdened health care system of Pakistan poses a serious challenge not only for the doctors but also for the multiple stakeholders involved in the community systems. The organizational mismanagement at all levels of health care makes it even more inefficient.

The following six immediate strategies for its prevention and control are recommended.

\section{Strategy at the government level}

Governments realize that diabetes and the related NCDs constitute one of the major challenges for development in the
21 st century. It brings about tremendous economic burden not only to the patients and their families but also the total health system and economies of the country are affected by the direct and indirect medical costs through manpower and other resource losses. ${ }^{57}$ This can be done by the following:

- Identifying existing skills and expertise related to diabetes within primary care and reducing inequalities in provision and quality of diabetes care across primary and secondary care.

- Assessing existing services against agreed standards to identify practice, training, and development needs.

- Providing appropriate training to relevant staff including postgraduate education sessions, diabetes online courses, train the trainer's programs, and mentorship.

- Gain experience of the clinical governance process using the diabetes framework.

Dissemination of the PROMPT guidelines shall be on priority. Also, inclusion of essential medicine for diabetes and related NCDs must be considered, leading to a reduction in chronic complications. This in effect means, every dollar invested in NCDs yields seven dollars in return.

\section{MNHSRC}

DROP shall be centralized at the ministry level and collaboration between PHRC and HRAB shall help in strengthening the registry. DROP-1 can be a good pilot arm for developing the robust methodology for DROP. IML Sindh, which has so far been a philanthropic private venture, 


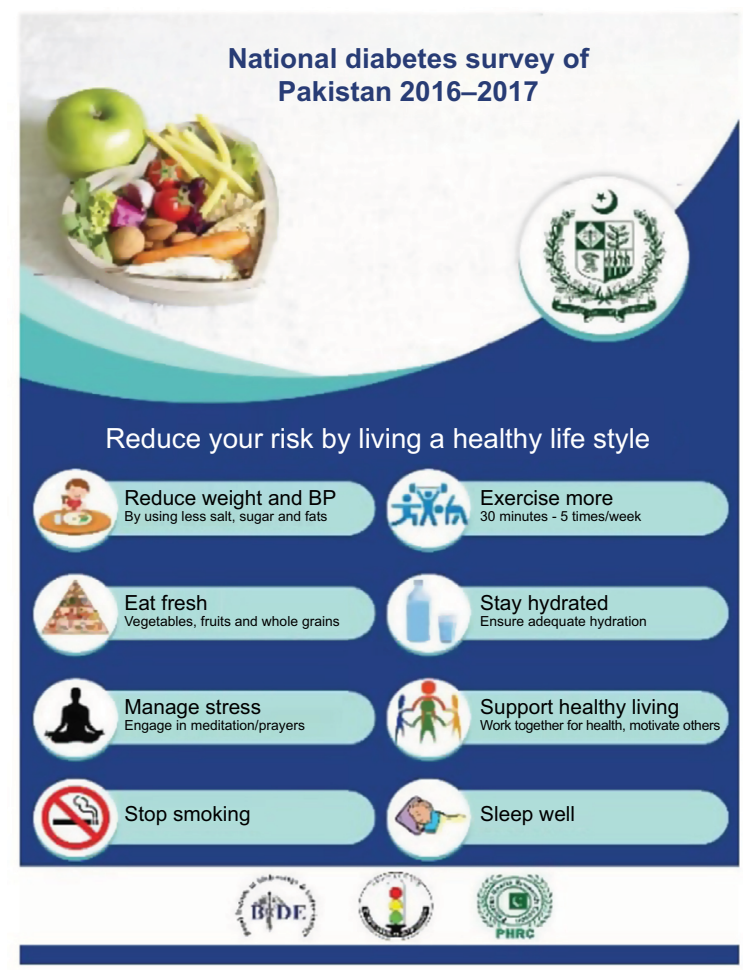

Figure 4 Risk Assessment of Pakistani Individual for Diabetes.

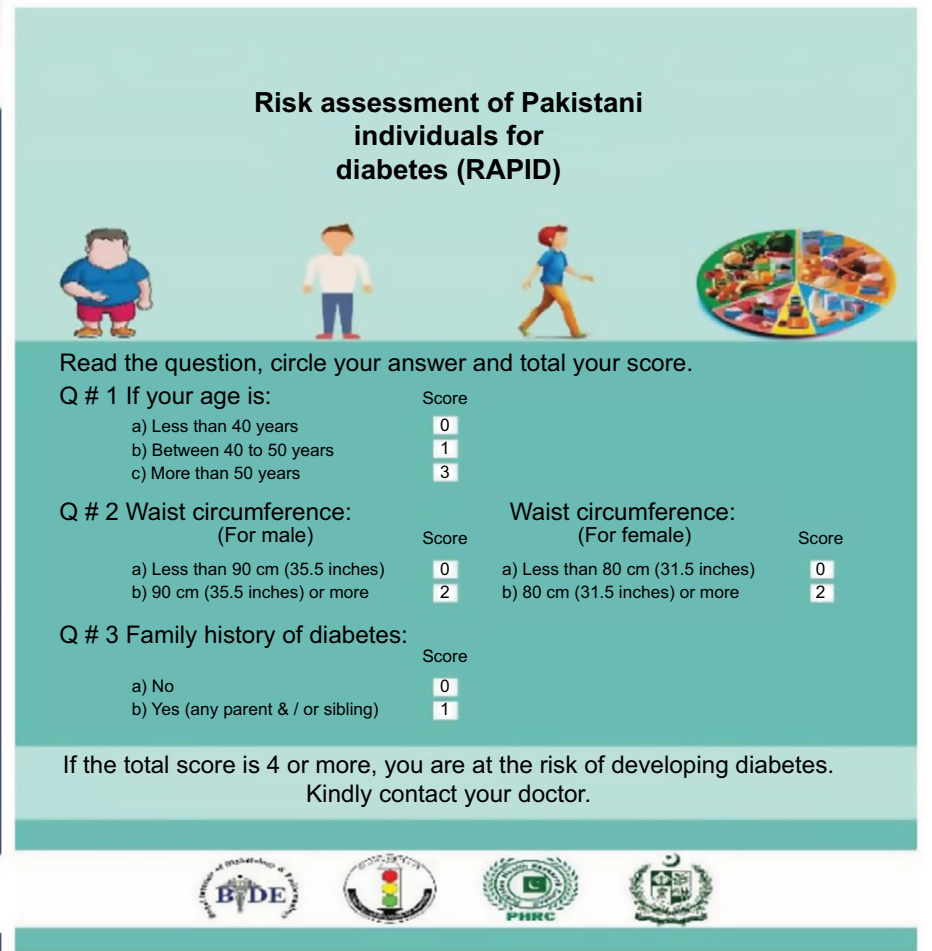

shall be taken on board by a private-public relationship to facilitate the processes for IML in other provinces of Pakistan.

\section{Strategy at the level of Communication and Mass Media Ministry}

There is a need to create awareness among masses about the causes and risk factors of T2DM. To achieve this task, print and electronic/social media shall be used. Similarly, community elders, religious leaders, and other public leaders shall be encouraged to play their role in creating awareness among the communities. Nationwide screening of diabetes through the RAPID tool using mobile technology and social media seems to be the most cost-effective population-based approach (Figure 4). Also, effective intervention is required at a general population level to increase intake of fruit and vegetables and avoid intake of junk foods in addition to promotion of physical activities. Primary prevention of diabetes through awareness campaigns by utilizing these tools is like to invest now and save later. ABCD in collaboration with PWGDF have started E-clinics for reducing the amputation rate with a diabetic foot. The Ministry shall facilitate regularization of such advisory board and E-clinics not only for diabetic foot but also for T1DM, GDM, and already proven cost-effective mobile eye screening and blindnesssaving programs.

\section{Strategy at the level of Education Ministry} NADEP shall be officially recognized and courses and curricula shall be regulated for NCDs at all levels including primary and secondary schools. PMDC regulates the training and courses for doctors, but other allied HCPs with important roles in NCDs shall have a roadmap defined by the Ministry of Education. Recognition of the diploma in diabetes education to strengthen NADEP on the pattern of Federation of European Nurses in Diabetes (FEND) shall be ensured. Master of Science in Public Health (MSPH) in NCDs for allied HCPs to develop NCD managers in preventive, management, policy making, corporate interventions shall be initiated. PWGDF activities to be facilitated for the reduction of amputation rates in Pakistan. ABCD shall be strengthened and work in collaboration with the ministries for developing guidelines customized to national socioeconomic demographic scenarios. The GDM advocacy board must be facilitated for widening its canvas to include maternal and child health for ensuring improvement not only in early diagnosis and management of GDM but also reduction in maternal mortality rate and transgenerational transmission of diabetes. 


\section{Strategy at the level of Ministries of Finance, Tax and Revenue, and Ministry of Food and Agriculture}

The Ministries of Finance, Tax, and Revenue should realize that NCDs are a drag on the economy. There is a need to collect robust data to see the impact of tax and price policies through census. The following fiscal measures are recommended:

- Enacting taxes on all tobacco products to discourage consumption and to raise revenue tobacco control program.

- Progressively eliminate national subsidies for all types of fats/oils and sugars.

- Imposition of heavy taxes on sugar-containing drinks.

\section{Strategy at the level of head of state}

There are five main priorities for head of state and government in accordance with the following recommendations of WHO for confronting NCDs (Figure 5):

- Provide leadership for NCD prevention and control as part of the development agenda.
- Be held accountable for national progress on NCDs.

- Fulfill obligations under the WHO framework convention on tobacco control.

- Act to ensure no industry interference in government policy making.

- Hold the UN System and Development Partners accountable for providing support on NCD prevention and control. $^{58}$

\section{Conclusion}

The rising incidence of diabetes in Pakistan is a big challenge. Future priority areas and interventional strategies include the following: implementing a diabetes health care service model in both rural and urban population of Pakistan by establishing diabetes clinics, units, and centers at primary, secondary, and tertiary care level, respectively, all over Pakistan using guidelines such as PROMPT and BRIGHT for SMBG etc, screening the population using RAPID, and registering the diabetes cases through DROP. Current management strategies and proposed future directions may successfully target the increasing incidence of diabetes in Pakistan.

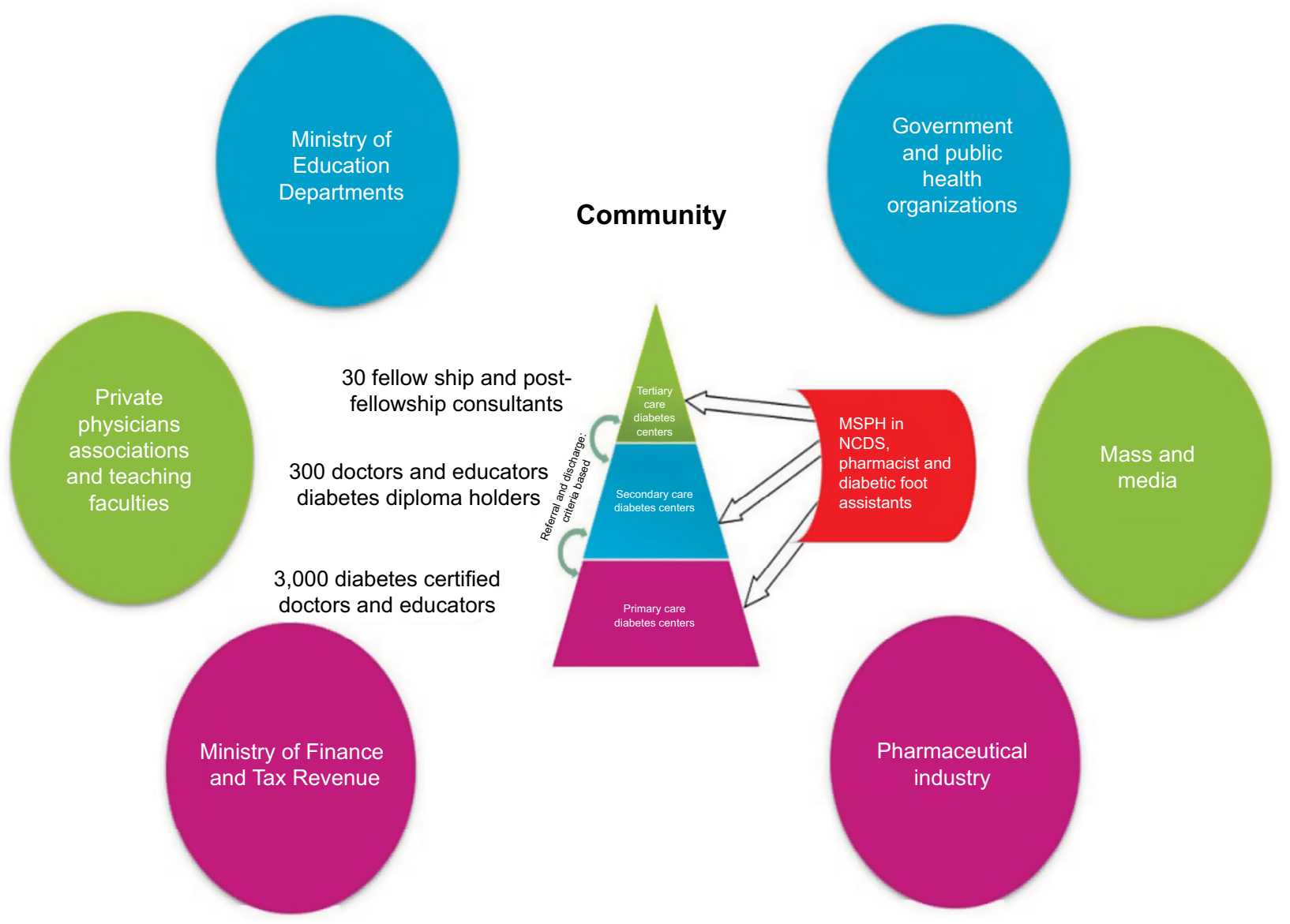

Figure 5 Proposed service model to target rising incidence of diabetes in Pakistan 


\section{Disclosure}

The authors report no conflicts of interest in this work.

\section{References}

1. PHRC. Final Book.cdr - Pakistan Health Research Council. Available from: phrc.org.pk/assets/final-book.pdf. Accessed July 27, 2018.

2. Pakistan Bureau of Statistics. Block Wise Provisional Summary Results of 6th Population \& Housing Census-2017. Available from: http://www. pbscensus.gov.pk/content/block-wise-provisional-summary-results-6thpopulation-housing-census-2017-january-03-2018. Accessed December 7, 2018.

3. Ministry of Finance [webpage on the Internet]. Pakistan Economic Survey 2016-17. Available from: www.finance.gov.pk/survey_1617. html. Accessed October 11, 2017.

4. National Health Vision, Pakistan, 2016-2025. Available from: http:// www.nationalplanningcycles.org/sites/default/files/planning_cycle_ repository/pakistan/national_health_vision_2016-25_30-08-2016.pdf. Accessed December 07, 2018.

5. Lady Health Workers in Pakistan - Harvard University. Available from: https://cdn2.sph.harvard.edu/wp-content/uploads/sites/32/2014/09/ HSPH-Pakistan5.pdf. Accessed December 07, 2018.

6. Jafar TH, Haaland BA, Rahman A, et al. Non-communicable diseases and injuries in Pakistan: strategic priorities. Lancet. 2013;381(9885):2281-2290.

7. Basit A, Fawwad A, Qureshi H, Shera AS; NDSP Members. Prevalence of diabetes, pre-diabetes and associated risk factors: second National Diabetes Survey of Pakistan (NDSP), 2016-2017. BMJ Open. 2018;8(8):e020961.

8. Shera AS, Jawad F, Maqsood A. Prevalence of diabetes in Pakistan. Diabetes Res Clin Pract. 2007;76(2):219-222.

9. Hakeem R, Fawwad A. Diabetes in Pakistan: epidemiology, determinants and prevention. J Diabetol. 2010;1(3):3.

10. Basit A, Shera AS. Prevalence of metabolic syndrome in Pakistan. Metab Syndr Relat Disord. 2008;6(3):171-175.

11. Basit A, Riaz M. Diabetes prevention in a challenging environment. Prevent Diab. 2013;10:84-93.

12. WHO [webpage on the Internet]. Pakistan: country profiles Nutritional Landscape Information System. Available from: http://apps.who.int/ nutrition/landscape/report.aspx?iso=PAK\&rid=1620. Accessed July 31, 2018.

13. Rani F, Safdar NF. A cross sectional study assessing the prevalence of modifiable risk factors of diet related chronic disease in tertiary care hospital employees. Ann Abbasi Shaheed Hosp Karachi Med Dent Coll. 2016;21(1):9-16.

14. Zia A, Bhatti A, Jalil F, et al. Prevalence of type 2 diabetes-associated complications in Pakistan. Int $J$ Diabetes Dev Ctries. 2016;36(2):179-188.

15. Abro M, Zafar AB, Fawwad A, et al. Prevalence of diabetic micro vascular complications at a tertiary care unit of Karachi, Pakistan. Int J Diabetes Dev Ctries. 2018;3(1):1-6.

16. Basit A, Nawaz A. Preventing diabetes-related amputations in a developing country-steps in the right direction. Diabetes Voice. 2013;58(1) 36-39.

17. Ali SM, Fareed A, Humail SM, et al. The personal cost of diabetic foot disease in the developing world-a study from Pakistan. Diabet Med. 2008;25(10):1231-1233.

18. Heartfile. National Action Plan - NCDs - Pakistan. Available from: www.heartfile.org/pdf/NAPmain.pdf. Accessed August 1, 2018.

19. WHO. Global Report on Diabetes - World Health Organization. Available from: apps.who.int/iris/bitstream/10665/204871/1/9789241565257_ eng.pdf. Accessed July 31, 2018.

20. Excellent healthcare is being provided in Pakistan [webpage on the Internet]. Available from: https://www.dawn.com/news/1275382/whywere-hospitals-better-in-pakistan-during-the-colonial-times. Accessed December 07, 2018.
21. Ferguson WJ, Lemay CA, Hargraves JL, Gorodetsky T, Calista J. Developing community health worker diabetes training. Health Educ Res. 2012;27(4):755-765.

22. CPSP [homepage on the Internet]. Available from: https://www.cpsp. edu.pk/. Accessed 31, 2018.

23. IDF. Improving diabetes care with access and education. Available from: https://www.idf.org/component/attachments/attachments. html?id=589\&task. Accessed August 1, 2018.

24. WHO. Diabetes Action Now. Available from: www.who.int/diabetes/ actionnow/en/DANbooklet.pdf. Accessed August 1, 2018.

25. Basit A, Ghafoor E. IDF Middle East and North Africa Road map for better diabetes care. Diabetes Voice. 2018;65(1):17-18.

26. IWGDF [webpage on the Internet]. Diabetic Foot Care Assistants program. Available from: iwgdf.org/dfc-assistants/. Accessed July 29, 2018.

27. Baqai Institute of Diabetology and Endocrinology (BIDE). Certified Diabetic Foot Care Assistant Course. Available from: www.bideonline. com/CertifiedDiabeticFootCare.aspx. Accessed July 30, 2018.

28. IWGDF [webpage on the Internet]. Step-by-step. Available from: iwgdf. org/step-by-step. Accessed July 30, 2018.

29. Jawaid SA. Proceedings of NADEP Diabetes Foot Conference held at Lahore, Pakistan (August 10-12, 2018). Pak J Med Sci. 2018;34(5):1307-1316.

30. HRAB [homepage on the Internet]. About Us. Available from: http:// healthrab.org/aboutus.html. Accessed July 30, 2018.

31. Research Department - Baqai Institute of Diabetology. Available from: http://www.bideonline.com/Research-Introduction.aspx. Accessed December 07, 2018.

32. Lindström J, Louheranta A, Mannelin M, et al. The Finnish Diabetes Prevention Study (DPS): Lifestyle intervention and 3-year results on diet and physical activity. Diabetes Care. 2003;26(12):3230-3236.

33. Khan MU. Lifestyle modification in the prevention of type II diabetes mellitus. Oman Med J. 2012;27(2):170-171.

34. DAP [webpage on the Internet]. About DAP. Available from: www.dap. org.pk/aboutDAP.html. Accessed July 30, 2018.

35. Objectives - NADEP. Available from: http://www.nadep.org.pk/About. html. Accessed December 07, 2018.

36. Riaz M, Basit A, Hydrie MZ, et al. Risk assessment of Pakistani individuals for diabetes (RAPID). Prim Care Diabetes. 2012;6(4): 297-302.

37. Štiglic G, Fijačko N, Stožer A, Sheikh A, Pajnkihar M. Validation of the Finnish Diabetes Risk Score (FINDRISC) questionnaire for undiagnosed type 2 diabetes screening in the Slovenian working population. Diabetes Res Clin Pract. 2016;120:194-197.

38. Hydrie MZ, Basit A, Hakeem R, Ahmadani MY, Masood MQ. Children's health is insulin and lipid dependent. Pak J Nutr. 2004;3(2):128-133.

39. Misra A, Vikram NK, Sharma R, Basit A. High prevalence of obesity and associated risk factors in urban children in India and Pakistan highlights immediate need to initiate primary prevention program for diabetes and coronary heart disease in schools. Diabetes Res Clin Pract. 2006;71(1):101-102.

40. Basit A, Danish Alvi SF, Fawwad A, Ahmed K, Yakoob Ahmedani M, Hakeem R. Temporal changes in the prevalence of diabetes, impaired fasting glucose and its associated risk factors in the rural area of Baluchistan. Diabetes Res Clin Pract. 2011;94(3):456-462.

41. Nishtar S. Diabetes is a serious women's health issue. Diabetes Voice. 2017;64(3):4-5.

42. Nishtar S. Prevention of non-communicable diseases in Pakistan: an integrated partnership-based model. Health Res Policy Syst. 2004;2(1):7.

43. Finance Minister unveils Federal Budget 2016-2017 - Daily Pakistan [homepage on the Internet]. Available from: http://www.finance.gov.pk/ budget/budget_in_brief_2016_17.pdf. Accessed December 07, 2018.

44. Nishtar S, Shera S. Diabetes prevention and control as a part of an integrated non-communicable disease strategy: the Pakistan approach. Pract Diab Int. 2006;23(8):332-334.

45. Sherin A. National diabetes action plan of Pakistan: need and challenges. Khyber Med Univ J. 2015;7(1):1-2. 
46. PDLF 2014 delivers outline of Islamabad call for diabetes control. Available from: https:/www.thenews.com.pk/archive/print/488460pdlf-2014-delivers-outline-of-islamabad-call-for-diabetes-control. Accessed December 07, 2018.

47. Nishtar S, Faruqui AM, Mattu MA, Mohamud KB, Ahmed A. The national action plan for the prevention and control of non-communicable diseases and health promotion in Pakistan-cardiovascular diseases. $J$ Pak Med Assoc. 2004;54(12 Suppl 3):S14-S25.

48. Shera AS, Basit A; Team P. Pakistan's Recommendations for Optimal Management of diabetes from Primary to Tertiary care level (PROMPT). Pak J Med Sci. 2017;33(5):1279.

49. Yan P, Tan EK, Choo JC, Liew CF, Lau T, Waters DD. Statin-centric versus low-density lipoprotein-centric approach for atherosclerotic cardiovascular disease prevention: a Singapore perspective. Singapore Med J. 2016;57(7):360-367.

50. Saito Y, Morimoto T, Ogawa H, et al. Low-dose aspirin therapy in patients with type 2 diabetes and reduced glomerular filtration rate: subanalysis from the JPAD trial. Diabetes Care. 2011;34(2): 280-285.

51. Schrier RW, Estacio RO, Mehler PS, Hiatt WR. Appropriate blood pressure control in hypertensive and normotensive type 2 diabetes mellitus: a summary of the ABCD trial. Nat Clin Pract Nephrol. 2007;3(8): $428-438$.
52. Pyŏrälä K, Pedersen TR, Kjekshus J, Faergeman O, Olsson AG, Thorgeirsson $\mathrm{G}$. Cholesterol lowering with simvastatin improves prognosis of diabetic patients with coronary heart disease. A subgroup analysis of the Scandinavian Simvastatin Survival Study (4S). Diabetes Care. 1997;20(4):614-620.

53. Basit A, Khan A, Khan RA. BRIGHT guidelines on self-monitoring of blood glucose. Pak J Med Sci. 2014;30(5):1150-1155.

54. Fawwad A, Ahmedani MY, Basit A. Integrated and comprehensive care of people with type 1 diabetes in a resource poor environment- "Insulin My Life (IML)” project. Int J Adv Res. 2017;5(4):1339-1342.

55. DROP | Diabetes Registry of Pakistan [homepage on the Internet]. Available from: drop.com.pk/. Accessed July 30, 2018.

56. Flickr [webpage on the Internet]. The My Life with Diabetes art competition was organized by the IDF Life for a Child Programme. Available from: https://www.flickr.com/photos/idf/sets/72157669229594901/. Accessed July 2, 2016.

57. Researchgate [database on the Internet]. Diabetes Mellitus in Pakistan: A major. Available from: https://www.researchgate.net/publication/287644898_Diabetes_Mellitus_in_Pakistan_A_major_Public_Health_Concern. Accessed July 22, 2018.

58. WHO [webpage on the Internet]. Global Action Plan for the Prevention and Control of NCDs. Available from: www.who.int/nmh/events/ ncd_action_plan/en/. Accessed August 1, 2018.
Diabetes, Metabolic Syndrome and Obesity: Targets and Therapy is an international, peer-reviewed open-access journal committed to the rapid publication of the latest laboratory and clinical findings in the fields of diabetes, metabolic syndrome and obesity research. Original research, review, case reports, hypothesis formation, expert opinion and commentaries are all considered for publication. The manuscript management system is completely online and includes a very quick and fair peer-review system, which is all easy to use. Visit http://www.dovepress.com/testimonials.php to read real quotes from published authors. 